\title{
Arte e consumo
}

\section{[Andy Warhol, From A to B and Back Again, Whitney Museum of American Art, Nova York]}

\author{
Luiz Sérgio de Oliveira ${ }^{1}$
}

http://dx.doi.org/10.22409/poiesis. 1932.165-174

\begin{abstract}
A visita a uma exposição de obras de Andy Warhol em um museu nova-iorquino na semana do Thanksgiving pode transformar-se em uma tarefa bastante custosa, com diferentes gramaturas de dificuldades às beiras de uma impossibilidade. Longas filas na área externa de acesso ao museu sob temperatura muito baixa para os padrões brasileiros (ou mesmo para outros padrões); extensa linha de pessoas que avança entre sinuosidades em direção às bilheterias no lobby do museu, mantida inerte e imobilizada enquanto aguarda que os salões de exposição nos andares superiores abram espaços para acolher novos visitantes. Diante desse cenário, quase uma prova de obstáculos, e após uma rápida consulta a um funcionário do museu, a decisão de voltar em outro dia pareceu ser a mais adequada, a mais sensata ou mesmo a única possível.
\end{abstract}

\footnotetext{
${ }^{1}$ Luiz Sérgio de Oliveira é artista e professor titular em Poéticas Contemporâneas da Universidade Federal Fluminense. Doutor em Artes Visuais pelo PPGAV-EBA-UFRJ (2006), Mestre em Arte pela Universidade de Nova York (NYU, 1991) e graduado em Artes Visuais (pintura) pela EBA-UFRJ (1978). É professor do Programa de PósGraduação em Estudos Contemporâneos das Artes da UFF e Editor da Revista Poiésis.

E-mail: luizsergiodeoliveira.br@gmail.com
} 
De qualquer maneira, a observação desse acúmulo de gentes na disputa por um acesso à mostra de Andy Warhol no Whitney Museum deflagrava de imediato algumas reflexões, com manifesta constatação de que os 15 minutos preconizados por Warhol haviam se transformado em um espetáculo permanente. Um espetáculo que atrai, indistintamente, os sempre fiéis aficionados do mundo da arte; os turistas que, vindos de diferentes partes do mundo, ajudam a transformar a visita aos museus de arte de Nova York em parada (semi)obrigatória; os/as jovens modelos (ou aspirantes a) que pareciam estonteados / estonteadas e sem rumo depois da falência da Interview, revista pop criada por Andy Warhol há cinquenta anos. No entanto, talvez o mais surpreendente tenha sido ver na(s) fila(s), e nos restaurantes de um entorno revitalizado e gentrificado, a presença de famílias que carreiam as características do tipo norte-americano, vindas desse enorme interior norte-americano, conservador "por natureza", que se alarga pelo vasto território dos Estados Unidos entre seus dois extremos: as costas leste e oeste. Famílias que se deslocaram para Nova York no final de semana do Thanksgiving para assistir à parada da Macy's pelas principais avenidas da cidade e que haviam incluído a visita à mostra do Warhol em seus desejos turísticos. O que haveria de comum entre o indelével conservadorismo dessas famílias-padrão norte-americanas e a vida descomedida e desregrada de Warhol e de seus amigos/amigas da Factory? É possível entender que os filtros da história, assim como a ação seletiva e implacável do sistema de arte, acabam por aproximar tudo e todos de acordo com seus próprios interesses, neutralizando sob a chancela do espetáculo as postulações mais virulentas das produções dos/as artistas?

A mostra de Andy Warhol - From A to $B$ and Back Again - se espalha por três andares do Whitney Museum às margens do Hudson River. A parte principal da exposição está instalada no quinto andar, onde a multidão de visitantes pode percorrer os salões e a produção do mestre da Pop Art norte-americana antes de iniciar sua escalada invertida e se dirigir para os andares inferiores. Nesses espaços expositivos ocupados pelas obras mais famosas de Andy Warhol, pequenos grupos de visitantes - em silêncio e em isolamento induzido pelo uso de fones de ouvido - acompanhavam as explicações (de) profissionais do departamento de educação do museu que, com a ajuda de um pequeno microfone, guiavam

Poiésis, Niterói, v. 19, n. 32, jul./dez. 2018. 
a visita. Esses visitantes viviam a expectativa de que assim pudessem entender o que teria se passado na cabeça e nos processos de criação daquela figura excêntrica que, nascido como Andrew Warhola, Jr. em Pittsburgh, Pensilvânia, em 1928 e falecido em 1987 em Nova York, cidade que ele - Warhol - fez como trampolim para catapultar sua obra e se tornar um dos grandes nomes da Pop internacional. Enquanto percorríamos os espaços expositivos do quinto andar do Whitney, pudemos testemunhar os deslocamentos de pelo menos três grupos em visitas "educativas" simultâneas que se esgueiravam entre salas, obras, passagens e um enorme acúmulo de visitantes.

Como era de se esperar de uma mostra deste vulto organizada por um museu da importância do Whitney no cenário internacional da arte, as obras de Andy Warhol que o tornaram mundialmente famoso estavam reunidas naquela que poderia ser uma coleção ideal dedicada ao artista. Logo na entrada do quinto andar, uma montagem com 32 latas de sopa Campbell (Fig. 1), junto às Brillo Boxes (Fig. 2) que tanto intrigaram a Arthur Danto e a outros tantos desde a primeira aparição na Stable Gallery de Nova York em abril de 1964. Dobrando em outra sala, Marilyn Monroe, Marlon Brando, Lyz Taylor, Elvis Presley (Fig. 3), repetidos, replicados, multiplicados diante de olhos ávidos que valorizam esses instantes de encontro com a arte. Neste cenário de consumo e de espetacularização que parece tratar indistintamente assuntos e questões as mais distintas, a série dos desastres e das execuções em um flerte macabro e definitivo com a morte não poderia estar ausente (Fig. 4). Quase ao término do périplo pelos salões do quinto andar, um gigantesco retrato de Mao Tsé-Tung, em uma quase escala Praça da Paz Celestial, evidencia a magnitude dos esforços para reunir no Whitney aquelas obras de Andy Warhol. (Fig. 5)

A descida pelas escadas que levam ao terceiro andar traz uma referência involuntária à antiga sede do Whitney abrigada em outros tempos na Madison Avenue: nos dois casos, uma escada isolada em um fosso do alto do qual desce, como uma cascata, uma obra de arte. No passado, uma arte sonora cuja autoria se perdeu no tempo e na memória; na sede atual do museu, uma cascata de lâmpadas e de luz assinada por Félix GonzalezTorres, Untitled (America), 1994. 

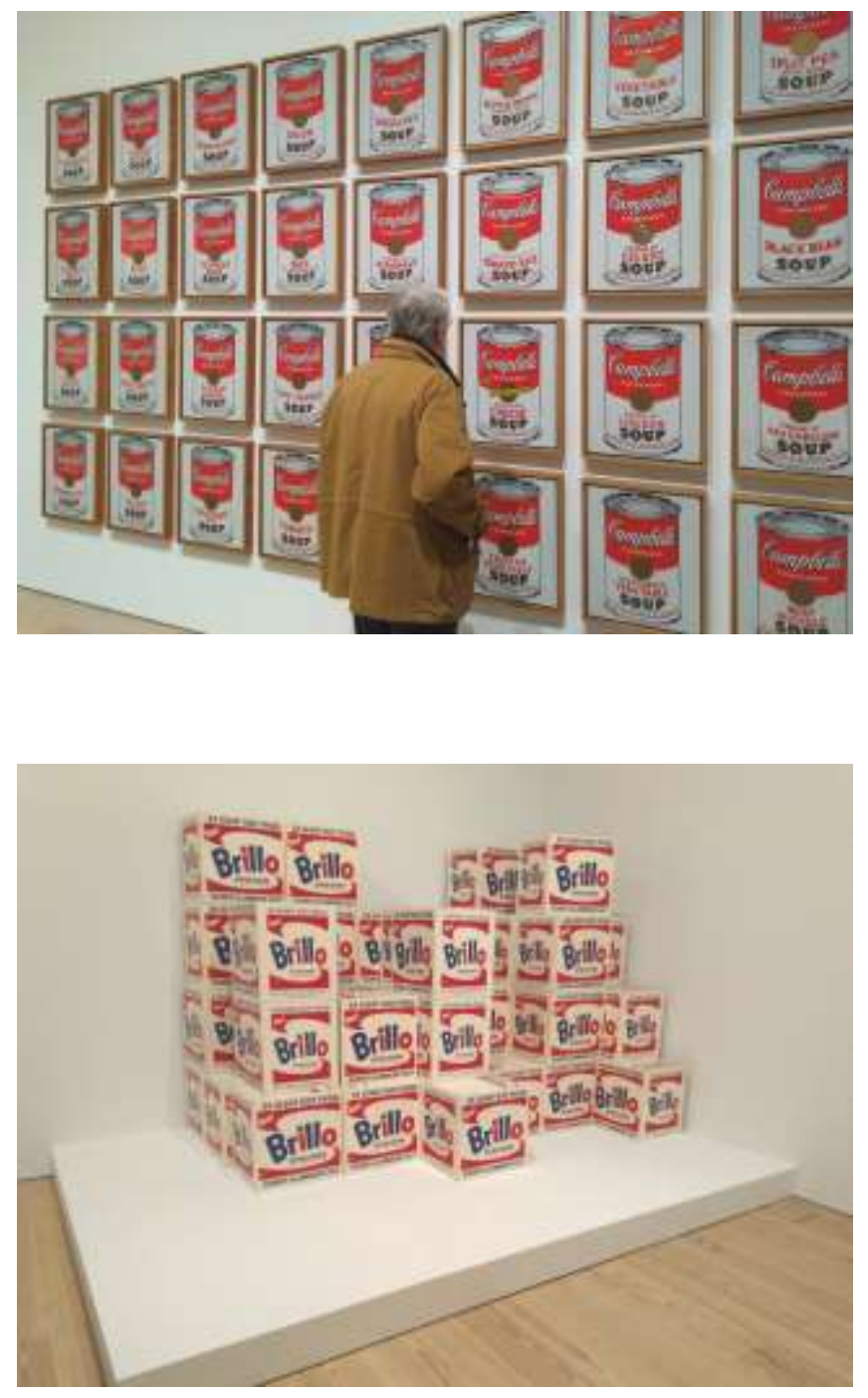

Poiésis, Niterói, v. 19, n. 32, jul./dez. 2018. 


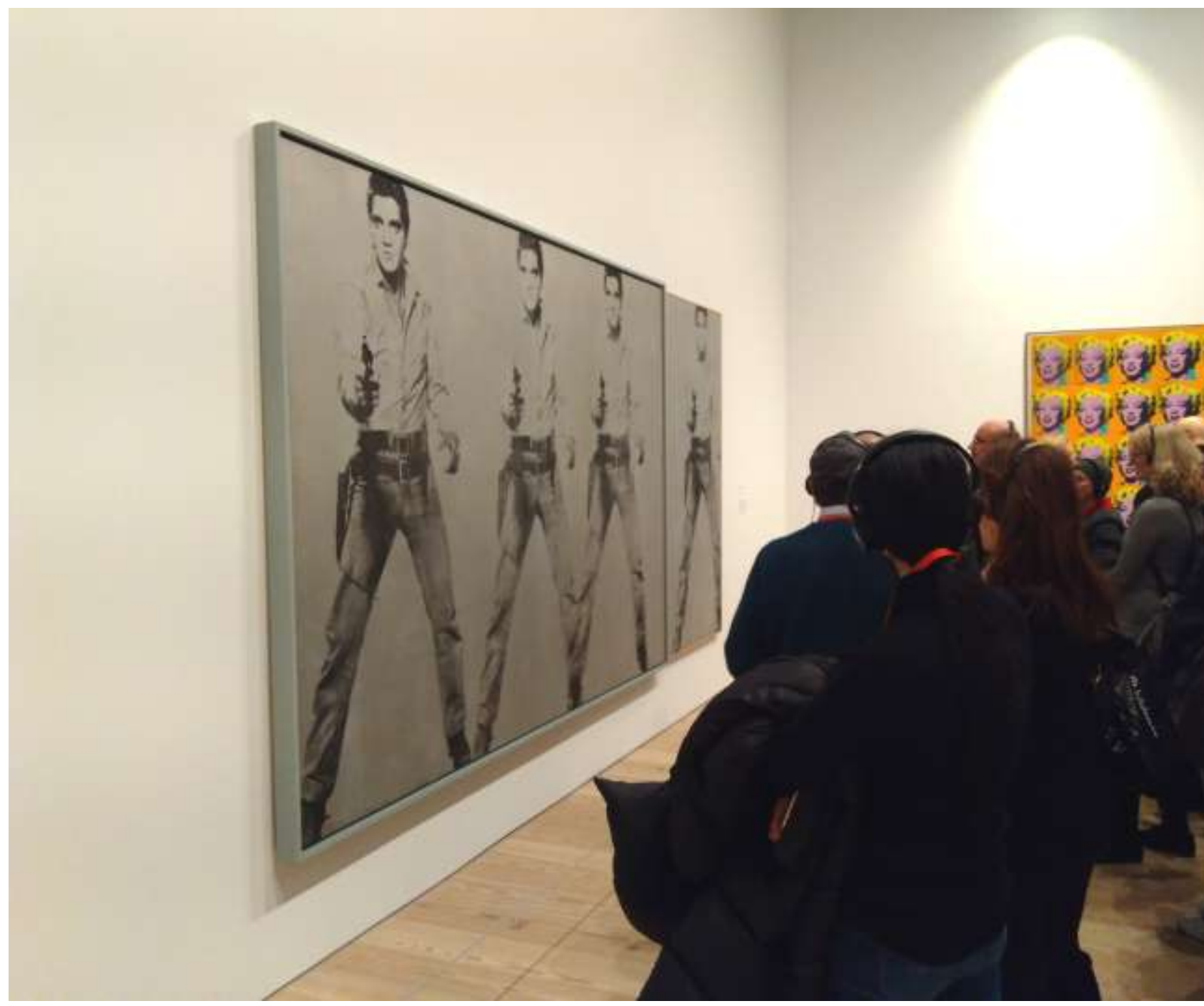

Poiésis, Niterói, v. 19, n. 32, jul./dez. 2018. 


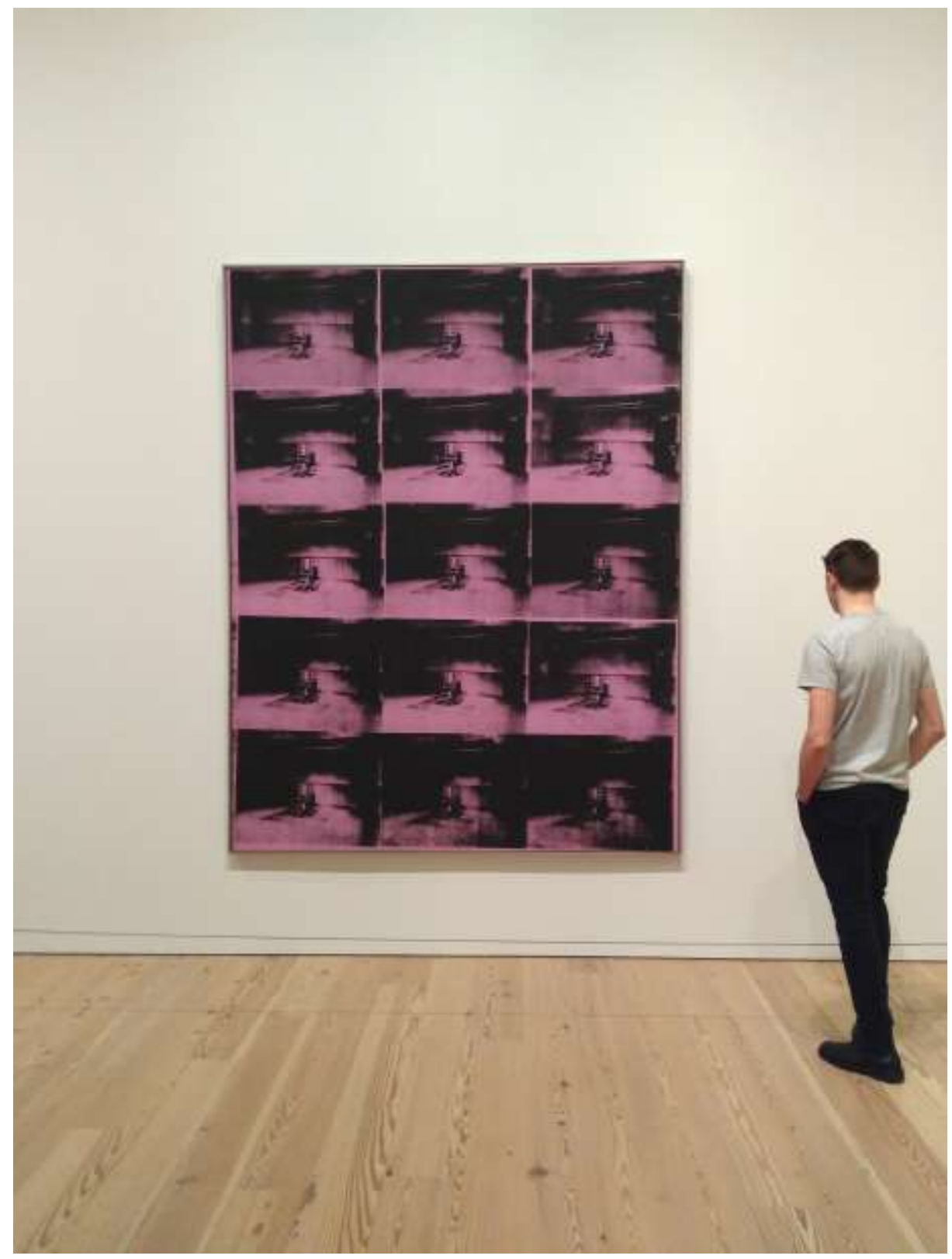

Poiésis, Niterói, v. 19, n. 32, jul./dez. 2018. 


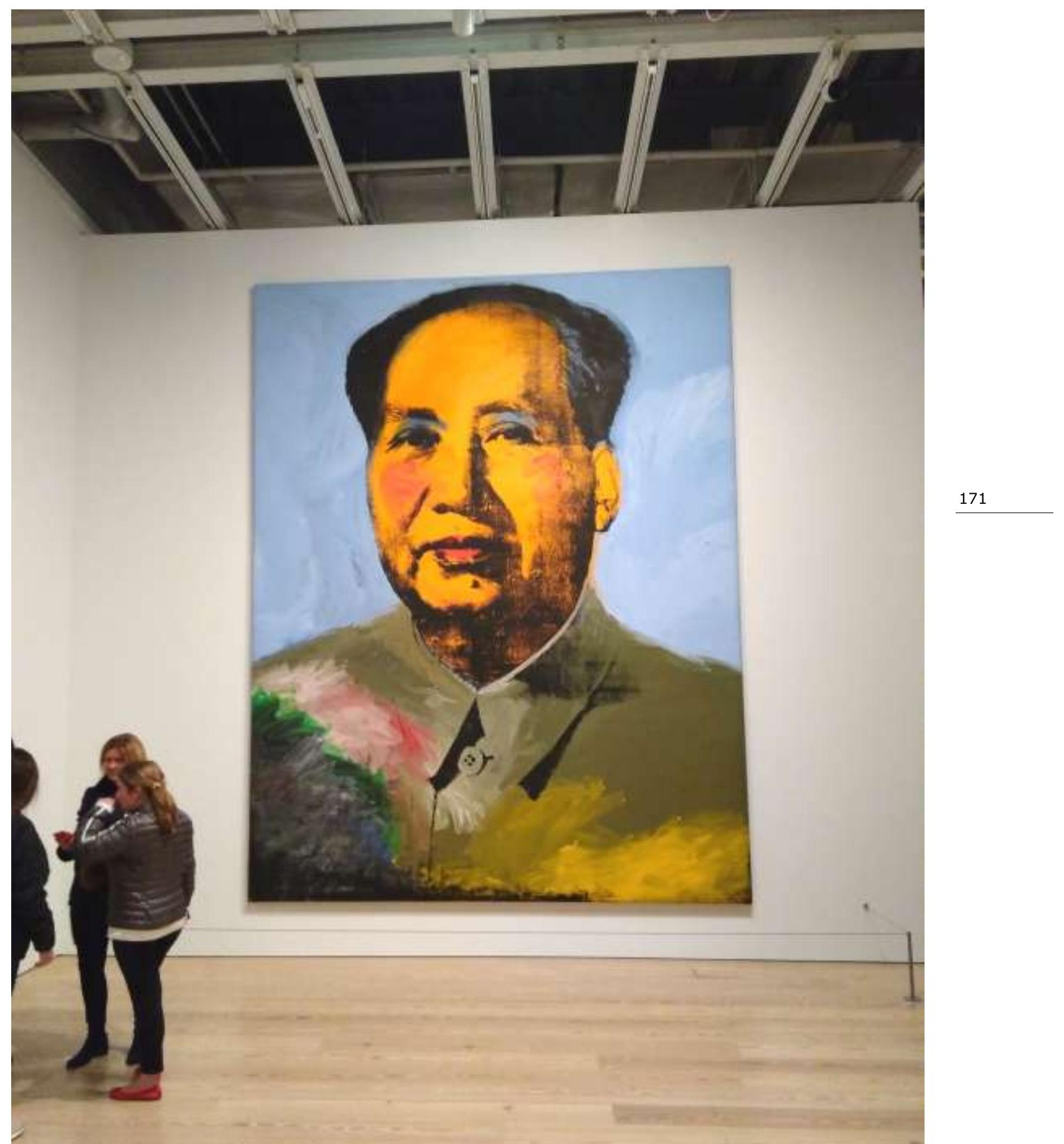


No terceiro andar se concentram trabalhos sobre papel e vídeos criados e produzidos por Warhol. Neste novo cenário, a exposição ganha ares de arquivo e de pesquisa, com pequenos monitores e fones de ouvido, agora conectados diretamente à produção do artista, convidando os visitantes a um pausa no ritmo um tanto frenético próprio às visitas de megaexposições, antes de uma nova descida de mais dois andares em direção à última parte de From $A$ to $B$ and Back Again.

A seção Portraits está instalada em um espaço semioculto do andar térreo do museu. Em uma sala ampla no estilo lounge, a visita aos retratos de Andy Warhol ganha colorações de um jogo: who's who neste universo pop de Andy Warhol povoado por celebridades? Artistas, colecionadores, businessmen, atletas, modelos, socialites e qualquer um/a disposto a pagar por um retrato assinado por Andy Warhol. Entre 1968 e 1987, foram centenas de encomendas (Fig. 6) que ajudaram o artista a financiar seus projetos em diferentes áreas, tais como cinema, televisão, publicações e música.

Em uma entrevista, Warhol lembrava que eventualmente alguns retratados diziam sentir a ausência de um toque do artista, da marca do pintor em seus retratos, algo que era decorrência da técnica por ele utilizada: polaroide + serigrafia. Para evitar descontentamentos e frustrações, Warhol, ao seu melhor estilo, decidiu-se por eventualmente aplicar algumas pinceladas - rápidas e largas - de tinta acrílica semitransparente de maneira a deixar seu gesto de artista registrado na superfície da tela e assim garantir a satisfação do cliente.

Neste universo marcado por cores ácidas e vibrantes, nos deparamos com um painel pleno de rostos conhecidos, eventualmente famosos, outros nem tanto, a instigar muitos/muitas daqueles que circulavam pela sala com uma interjeição estampada em seus rostos que mal conseguiam dissimular: "eu também deveria estar nesta parede!" Ou, com maior precisão: "I should be on this wall, too!"

Poiésis, Niterói, v. 19, n. 32, jul./dez. 2018. 


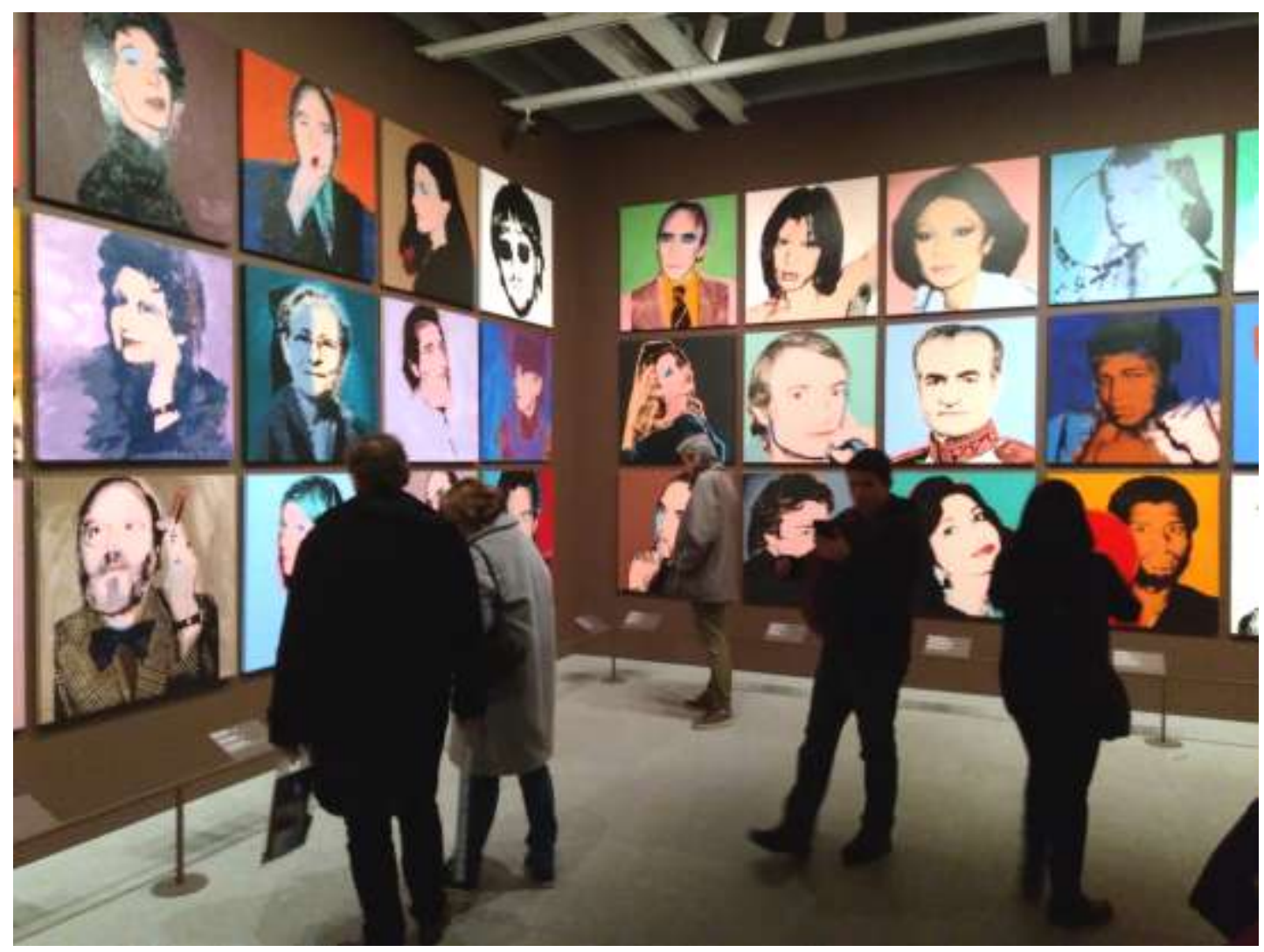


Fig. 1 - Andy Warhol, Campbell's Soup Cans, 1962.

casein, acrylic, and graphite on linen, 32 panels

(Museum of Modern Art, Nova York)

Fig. 2 - Andy Warhol, Brillo Boxes (Soap Pads), 1964.

silkscreen ink and house paint on plywood

(Museum of Modern Art, Nova York)

Fig. 3 - Andy Warhol, Lavender Disaster, 1963.

Acrylic, silkscreen ink, and pencil on linen

(The Menil Collection, Houston)

Fig. 4 - Andy Warhol, Triple Elvis (Ferus Type), 1963.

silver paint, spray paint, and silkscreen ink

(San Francisco Museum of Modern Art)

Fig. 5 - Andy Warhol, Mao, 1972.

acrylic, silkscreen ink, and graphite on linen

(The Art Institute of Chicago)

Fig. 6 - Andy Warhol (vários retratos datados de 1968 a 1987)

técnicas variadas; coleções diversas

(Fotos: Luiz Sérgio de Oliveira)

Andy Warhol, From $A$ to $B$ and Back Again, em exposição no Whitney Museum of American Art de Nova York de 12 de novembro de 2018 a 31 de março de 2019.

Curadoria de Donna De Salvo com Christie Mitchell e Mark Loiacono.

Mais informações: https://whitney.org/Exhibitions/AndyWarhol/

Como citar: OLIVEIRA, Luiz Sérgio de. Arte e consumo [resenha crítica da mostra de Andy Warhol, From A to B and Back Again, Whitney Museum of American Art, Nova York]. Poiésis, Niterói, v. 19, n. 32, p. 165-174, jul./dez. 2018. doi: http://dx.doi.org/10.22409/poiesis.1932.165-174

Poiésis, Niterói, v. 19, n. 32, jul./dez. 2018. 